\title{
Streptococcal Infection
}

National Cancer Institute

\section{Source}

National Cancer Institute. Streptococcal Infection. NCI Thesaurus. Code C87062.

Any of the several infectious disorders caused by members of streptococcus, a genus of gram positive bacteria belong ing to the family Streptococcaceae. Streptococcal infections are classified into Groups A, B, C, D and G. 